\title{
TOWARDS AN INTEGRATED FRAMEWORK FOR STUDYING INFORMATION AND COMMUNICATION TECHNOLOGY (ICT) ADOPTION FROM A DYNAMIC PROCESS PERSPECTIVE
}

\author{
Sunday C. Eze \\ Department of Business Studies \\ Landmark University Oma-Aran, Kwara State, Nigeria
}

\begin{abstract}
Information and Communication Technology (ICT) adoption research especially in small and medium enterprises (SMEs) has moved from a simple adopters' participation process to involving diverse actors that continually interact and influence the process. Small businesses need constantly interact with various human and non-human actors to keep up with the emerging ICT development and benefit from the emerging opportunities (Eze et al 2012, Eze, 2013; Eze et al 2014). However; this has proved difficult. This paper reviews three prominent theories of ICT adoption, integrates and develops a model from them to assist researchers make substantial theoretical advancements in this area.
\end{abstract}

KEYWORDS: Social -Tech Theories, Dynamic and Evolutionary Process, Emerging ICT, Adoption, SMEs

\section{INTRODUCTION}

The role ICT plays in business and managerial efficiency has made organisations to constantly invest their time and money to improve their performance however, what is still surprising is that studies are yet to produce a better account of the discipline to guide organisations (Bostrom et al, 2009) and researchers in understanding dynamic process of emerging information technology (IT). This is because most studies have focused extensively on the technology aspect and ignored the roles played by human agency (Barett, 2006) and/or end up with limited examination of the roles played by technology (Bostrom et al, 2009). Studies that focus on the technical aspect assume that the outcome of a piece of technology is only attributed to the feature of the technology instead of humans (Tatnall and Jerzy, 2003). These theories are deterministic in nature and assume that factors external to an individual substantially shapes the organisations outcome, and actors choice are considered as marginal, trivial or illusionary (Bostrom et al, 2009). Theories in this area are problematic because they de-emphasis the roles played by human agency and yet studies exist within social context where actors manipulate agency during change process (Bostrom et al 2009).

On the contrary, social determinism is concerned with the examination of the social interactions with the technology and points out that "social categories" can be deployed to examine change (Tatnall and Jerzy, 2003). The approach corresponds to what Markus and Robey (1988 p. 587) called organisation imperative where "human actors construct information systems to satisfied organisation needs for information". Examples of such theory are the process theories which emphasis on the social construction of meaning, social formation and the symbolic interaction theory which looked at the importance of communication in creating social order (Desanctics and Poole, 1994). However, one limitation of this approach is that the roles played by 
technology are less accounted for (Markus and Robey 1988; Bostrom et al 2009) when studying IT adoption, despite studies (Callon, 1986; Latour, 2005) argue that it is the interactions between the social -technical perspectives that makes Information Systems (IS) unique from other disciplines (Hanseth, Aanestad, and Berg, 2004; Bostrom et al 2009). Vast number of adoption studies have focused on either of the approach despite, Bostrom et al (2009:18) note that: "Social-technical systems (STS) theories view any organisation work as consisting of social and technical subsystems interacting and influencing each other. As such, they offer a potential solution for the need in IS research for more integrated theories". The aim of this short paper is to review three social technical theories-Actor network theory (ANT) and Struturation Theory (ST) and Adaptive Struturation theory and integrate them to produce a more comprehensive framework to help make a theoretical advancements in this area.

\section{ACTOR NETWORK THEORY (ANT)}

ANT and its application (Callon, 1986; Bijker et al, 1989) within the information system discipline addresses the role technology play in the social setting and the process by which technology influences and is influenced by social elements over time (Mahring, 2004). The theory has been recognised as powerful and can assist researchers overcome the poor understanding of technology (lee and Oh 2006; Lee et al, 1997: Tatnall and Jerzy 2003). To better understand the emergence and use of information and communication technology, Hanseth, Aanestad, and Berg (2004) point out that ANT should be applied especially those of "commercially driven innovation networks". This theory has been used to understand the dynamic interaction of people and the technology during its design; development and adoption (see Tatnall and Jerzy 2003).

Early development and application of ANT was concerned with sociology of science (Callon, 1986; Latour, 1987; Lee et al 1997). This theory originated on the account that the study of technology can be extended to "sociological tool" for analysis (lee and Oh 2006).For instance, the Innovators that involves in technological development embody into the technology, the way such technology is been used, their motives, interests, prejudices and their version of the society, making it impossible to differentiate the technical from the social during the process of innovation. This makes the technical aspect of the developers social. As lee and Oh (2006) point out when actors consider human to be technical, technology becomes an entity in which innovators inscribe the social that they want to realise or come out with. Actor network involves an arrangement where both human and non-human actors are enrolled into a network. This process occurs by means of negotiation involving redinifinition, where the key or focal actor tries to impose roles and definitions to other actors (Tatnall and Jerzy, 2003). According to Lee et al (1997:470) the theory is concerned with the "creation and maintenance of human and nonhuman element, process of translation and inscription, the creation of black boxes or immutable mobiles and the degree of stability and irreversibility of networks and their elements".

According to Gao, (2005) increased attention has been gained from applying ANT by various researchers in technology adoption and design to brother areas. This theory has been applied in different context, such as "IT development, IT enabled organisation change, computer mediated communication and infrastructure standards" (Allan 2004; lee and Oh 2006). It offers a new ideas or concepts that can help us study the social and technical nature of Information systems (Lee et al 1997). However, to better understand the human and non-human actors and 
treat them at the same level, the theory must be based on three conventions: agnosticism, generalised symmetry and free association (Tatnall and Jerzy 2003). Agnosticism means that, all actors must be subjected to the same analytical process without any form of impartiality given to either human or non-human actors. Generalised symmetry offers an approach where different and conflicting views of actors in the same context are analysed based on "abstract and neutral vocabulary" in the same way for human and non-human actors and no special explanatory attention should be attached to any of these entities. On the other hand, free association requires the abandonment of all previous distinction between the technology and social (Tatnall and Jerzy 2003). This rules must guide the researchers accordingly when applying the theory, however, ANT has been subjected to a number of criticisms.

\section{CRITICISMS OF ANT}

Any social theory like ANT that has received ample attention is not without criticisms and researchers that aimed at using the theory must be aware of the criticisms and should be able to understand its limitations (Lee, et al 1997). One fundamental criticism and major attraction of ANT in IT research is the treatment of both human and non-human (technology) as members of actor networks. Most recent work on ANT has argued that this criticism is one that is baseless or "unfounded" (Hanseth, Aanestad, and Berg 2004). Though the authors accepted that ANT assumes everything as an actor network, they argue that this is equally the same in both human and technologies, and as all networks differ, so do technology and humans do. At least with regards to the functions they perform in organisation and social life and these differences comprise different actor networks.

Furthermore, ANT was criticised because it paid less attention to issues of social structures. The theory paid little attention on the way institutional forces shape the process of social interaction and emphasises more on how things are being done (Lee et al 2007; Allen 2004). Researchers of social technical change share similar idea with other social technical researchers on the assumption that some agents have stable interests and practices though, most actors argue that interests are subject to change; they tend to work on the assumption that actors have a relatively stable structure and will continue with their existing practices. Although actors' main goal is to understand social technical change, it cannot be fully examined in this way. Allen (2004) argues that structures and institutions will emerge and arrangement will stabilise if the delegation and controlling strategies are employed successfully. Hence institutions are part and cannot be detached from the strategies of the actors, and neither can it be reduced because what the key actors seek to hold in place is drawn from a structured environment (Allen 2004).

It is also controversial to claim or link the method of analysis employed by ANT to a larger, macro level analysis (Allen 2004). Researcher have claimed that ANT is a technique that bypasses micro and macro level analysis, however, in practice ANT is an excellent and explanatory device at the micro level, but it has fail to explain the events that immediately go beyond micro world of the actor (Allen, 2004; Hanseth, Aanestad, and Berg 2004). Lee et al (1997) and Allen, (2004) on the contrary, note that it is even difficult to avoid ANT analysis when making references with large social and cultural context as an aspect of an ANT analysis. However, one important question is how to bridge conceptually, the macro (organisational) and micro (individual) level analysis and at least retain the unique strengths of ANT analysis. 
Researchers have emphasis the combination of ANT with struturation theories and other concepts from other theories which serve as compliments (Allan, 2004, Hanseth, Aanestad, and Berg, 2004; lee et al, 1997) (example, technological frame, inclusion and configuration). These can help bridge the gap between actors and the structural elements. Drawing from Bijker idea, technological frame (see Bijker, 1992) is one of the processes that "link translation process of ANT with broader social and cultural processes" (Allen, 2004:173). It is used in this research as one of the core stages of emerging technologies and examined in subsequent sections. However, deploying only ANT in this study will limit the scope in studying dynamic and evolutionary process of ICT adoption since the propounders of the theory have revised and extended elements of it .To provide a better insight into the scope of the study, the researcher attempts to bridge the gap in ANT and integrate ANT with ST and AST as suggested by previous researchers (e.g Bijker, 1992; Hansth, Aanestad and Berg 2004; Lee at al, 1997) as a complimentary.

\section{STRUCTURATION PERSPECTIVES}

Structuration theory (ST) has been applied by many researchers. The theory has revealed important insights into the social process related to adoption and use of information technology and broadly emphasises on the importance of social structures. The core argument of the theory is that structures are only represented in the mind of human actors and/or as traces of human action (Bostrom et al 2009). Struturation represent a situation governing the continuity or change in structure leading to reproduction of social systems .The theory focuses on actors enacting structures, in that way they understand and come to use these structures ( Bostrom et al 2009). While studies appreciate the vital contributions of this theory however, the use of this theory to understand social technical organisation systems suffers two major limitations (Bostrom et al 2009).First, the theory broadly emphasised on the importance of social structures and consider technology as a social structure that constrains or enables certain human activities .It has been argued that such theory is rather a poor conceptualisation of technology because it examines technology in a limited way (Hanseth, Aanestad, and Berg, 2004; lee et al, 1997) and discharged the fact that structures are embedded by innovators during development and influence action (Bostrom et al 2009)

Secondly, structuration was developed to examine social systems within the society while the organisation systems are designed bearing a specific goal in mind. Despite providing a way to examine the reproduction of social structures, it does not explain why organisations adapt to certain structures (e.g. rules, resources, technology) and institutionalise those (Bostrom et al 2009). On the account of these limitations, structuration theory has its own limitation in complimenting ANT in studying the adoption and/or development of emerging technologies, though it recognises that actors enact structures and understand how the structures are been used (See inscription stage in the framework). Adaptive structuration theory (AST) is similar and this approach arguments structuration theory. The theory draws its assumptions from structuration view and compliments the two other approaches.

\section{ADAPTIVE STRUTURATION THEORY.}

AST examines the relationship between technology, the social structures and human' interaction in the organisation. This model focused on the social structures, the resources and rules of the technology and the organization as the basis for human activities. Social structures 
are what make social action to happen and it is social action that creates the structures. Hence, structures are rules resources, and capabilities (e.g humans) organised in a meaningful way as parts of the organisation. Rules are define as pattern people might adhere to for example when designing or adopting technology development, while resources do not occur naturally rather they represent what is been created by human action example technology (Desanctis and Poole, 1994).

Poole and Desancitics (2004) identified seven requirements for effective application of AST: identification of structures, description of structures, relationships among structures, appropriation of structures move, contextual impact or influence of structures, Influence of actors and Power dynamics. In these seven requirements, ANT and ST assumes similar position. For instance translation in ANT is achieved through displacements that require the exercise of power that may or may not achieve the intended outcome. ANT also tries to describe and identify all the entities involved and the relation among them. Thus, structures in AST can be considered as an integral part of actors' network and can as well represent actent in ANT. Thus the term actors (often refered to as actent) in ANT or structures in AST are matter of nomenclature- an act of giving names or matter of classifications. As suggested by Bostrom et al, (2009), AST makes structures and human agent part of the system, accounting for the interplay between technology|(non-human actors) and people (human actors).Furthermore, the three theories also emphasised on social structures but at different levels. However, the researcher recognises that ANT network might be bigger than the structuration approaches since anything can constitute actors in ANT network.

One major difference between AST and ANT is that ANT does not make any prior distinctions of human and non-human actor, but AST does not and considers social structures in a more detailed way. For instance, when ANT is used in the adoption and use of technology, for instance, all the factors influencing the adoption including that of human and non-human participants are considered as actors and all in terms of the network. (Tatnall and Jerzy, 2003)

On the contrary, Bostrom (2009:24) et al notes:

"AST allows structures to be separate from the actions or mind of the actors making structures and thus, making structures an objective part of the actors' context allowing them to play an active role in the process along with the actors-----as well as the full predictability of IS use in individual, group and organisation. This allows AST to preserve the predictive potential of a deterministic perspective, while accounting for interpretative flexibility of the process perspectives".

AST is a good complimentary theory to the other two theories and will help bridge conceptually, the gap in ANT and ST that by passes the distinctions between micro and macro level and focused more on micro (individual) level analysis. Drawing from these three perspectives enables one to adopt both interpretative and predictive approach in the study. In the paper core concepts in ANT was used to describe the evolution of emerging technology and the actors who are involved in the process, and draws from AST to preserve the predictive potential of deterministic approach as a complimentary approach to ANT, while ST emphasises more on the social relation among the human actors at the stages. These approaches are integrated together (see framework below). Drawing on ANT, key concept/stages of emerging technology: inscription, translation, framing and stabilisation are reviewed. 


\section{Stage one: Inscription}

Developing and/or adopting an innovation are studied in a way that belief shapes the innovation (Faraj et al, 2004). Belief here is regarded as technology and represents knowledge or the process of knowing, which constitutes the cognitive elements that emerge as the technology is put in place, enacted and interpreted (Faraj et al, 2004). The idea about inscription is that it is a form of anticipated features which actors try to instantiate or build as technology (Faraj et al, 2004). These depends on the organisations beliefs, organisation's prior pattern of use, social relation and the idea as to what the artefact is about and can do (Akrich, 1992; Faraj et al, 2004).The extent actors define what the functionalities of the technologies are constitute inscription. Thus, the definition given to inscription can be demonstrates in different ways. (a) It could mean the extent innovators invent and shape the technology. (b) How the actors and the technology interact. (c) The pattern in which these technologies are being used (Faraj et al, 2004). As actors inscribe their ideas, interests and beliefs in the technology and communicate them to various areas where they are applicable, it leads to stability of the network (Mahring et al., 2004).This guides users in behaving in a way that defines the structures and functions performed by the technology. By investigating inscription overtime, we can understand how the functions perform by the technology are influenced by actors. This process leads to a shift in a way new technology emerges and is implemented.

\section{Stage two: Translation}

The innovation process such as, translation and other concept from ANT has much to offer when considering the detail of adoption of an evolving innovation such as that of internet applications. Translation is defined as a means through which one entity gives a role to others. It refers to how actors seek the interest of other human actors to support their claims and have their interests represented in the inscription (Tatnall and Jerzy 2003; Gao, 2005) or convince them directly or indirectly in developing/ and or adopting new technologies (Faraj et al, 2004). Translation relates to the interaction among diverse set of actors (See figure----).Translation considers more on how organizational actors use and make the most out of the technology and how the innovation needs to be translated for its adoption and use to be achieved. It provides a means through which small delicate factors can be addressed in such instance of adoption (Tatnall and Jerzy 2003).

As suggested by Sarkker et al., (2006) there is no hard and fast rule about an effective translation rather, it depends on the situation. This is the process of redefinition and it is based on the solution offered by the key actors. The key actors impose or persuade other actor by means of coercion, or consent to accept the roles leading to establishment of a stable network where the proposed solution gained wider acceptance. To understand the adoption of new technologies, it is imperative to see the interaction as a negotiation that is concerned with both human and non-human actors.

\section{Stage three: Framing}

New technologies undergo modifications either by adding new features, improving upon the existing features especially when adopted by lead users (Faraj et al, 2004). This allows new or different ways of using these technologies to emerge. Such technologies hardly become successful if users do not accept the way they are used (Faraj et al, 2004). As mentioned earlier, studying the evolutionary stages of any technology requires a dynamic process of negotiation and renegotiation between those of the designers and the actual users (Faraj et al, 2004; Akrich, 1992; Guard and Rappa 1994). In the context of this paper, framing is considered in line with 
Faraj et al (2004) definition which means emerging outcomes as actors inscribe their beliefs, interests and values and negotiate for developing, and/or adopting new technology. Framing also constitute a bundle of features and functionalities of a technology. These functionalities represent the core of the technology immediately they become part of users' expectations, standards and the beliefs of the actors, making the process difficult to reverse (Faraj et al., 2004).This allows new versions of the technology to be incorporated once consensus are reached and the functionalities improved.

Technological frame structures interactions among the actors. It incorporates all the factors that influence interaction and lead to attribution of meaning to the innovation. These factors both enable and constrain certain kinds of actions (Faraj et al., 2004). Technological frames are maintained by social interaction and can be change by social interaction through the process of inclusion in the technological frame. Inclusion is defined as to what degree technological frame structures the actors' interaction. As Allan (2004) points out, actors might have a fixed method or idea about a problem and it solutions with regards to a technology, however, it is through the process of inclusion that new possibilities are opened. Technological frame directs or guides future development and implementation process of advance information communication technology.

Advance information communication technology (ICT) has relatively complicated structures. The performance of any technology will produce a critical impact if the adoption fits with the intention of original design. We and Ho (2005), note that during the process of implementing technology, actors in the organisation often discover some problem inherently unknown during the initiate stage. Organisations might have to adjust to achieve the benefits of the new technology. Business process may also be redesigned. This might also affect the relation of the organisation (Bygstad et al, 2005). This problem necessitates technology adaptation. It is at this stage that further adaptation (post adoption behaviour) of technology and /or the organisation process are re-examined involving fitting the technology into the organisation proper. This can take various forms.

\section{Stage four: Stabilisation}

To close a technology controversy, actors need to solve the identify problem. It is only when the problem is solved that stabilisation occurs. Stabilisation of technology is defined by Bijker et al, (1989) as the "disappearance of problems where the relevant groups (organisations) consider the problem as being solved. It is also considered as the successful implementation of the technology that leads to a stable network. It is expected at this stage that technology would be stable and the stakeholders convinced about the value of the network (Bygstad et al, 2005). However, innovation and businesses process might change; new technologies might evolve, thereby causing "closure by redefinition of a problem" (Bijker et al, 1989) or readjustment of the innovation to suit its purpose. Hence, the relationships between the various actors (human and non-human) at different stages of this process exemplify the ongoing struggles for the creation, adoption and adaptation of technology overtime (see framework). Previous sections highlights that the human and non-human element constitutes the network in ANT when considering how evolving technologies are adopted overtime. It also is important to consider the entities involved in the network because they are the backbone for the various activities that happen in the network 


\section{IDENTIFYING ENTITIES INVOLVED IN THE FRAMEWORK}

The complexity of the system needs to be taken into consideration such as the web of interaction from system actors themselves. One has to consider who is to be enrolled and what it takes in order to make such enrolment successful. Hence both human and nonhuman actors are defined in relation to it. Hence, the evolutionary stages of new technology can be considered as a strategy involving a system of relations (actants) (Ng-Kruelle, Rebne, Swatman and Hampe, 2005), and because of different associations, it is vital to examine the entities linked, and the existence of any intervening factors (see framework).

\section{Entities}

we recognise the key actor as the managers of SMEs and most often due to the nature and characteristics of SMEs and their social formation, most decision to development and/or adoption behaviour is determined by the managers, especially those that are founded on a single business idea. An external force like customers may also play a vital role in generating ideas and facilitates the adoption of new technology because they are the primary motives why these small businesses are in business. Development organisation (developers, owners of development organisation, organisations sales force /vendor, IT staff) are crucial in terms making decisions, designing and rolling out the new technology especially where SMEs cannot afford to build the technology in-house. It is necessary to also consider entities like the general public (government and its agencies) and society that directly do not form part of the developer or user organisation but can affect the behaviour of the entire process in terms of maintaining development standards. Emerging technologies represent all internet based applications such as software, computers/mobile applications, and other communication infrastructures and the factors (human and non-human) spelt out in the framework below.

\section{CONCEPTUAL FRAMEWORK}

Theories produced by researchers focus on a small number of social technical perspectives which either addressing the technical or the social approach in isolation or predict empirical findings in a very narrow way. Literature shows that there is an improvement in productivity, easier work translation when such theories are integrated and use in studies (Bostrom, et al 2009). Small number of researches also combines different research methods. According to Bostrom, et al (2009) researchers do recognize the challenges of integrating their findings into a very large integrated theory that addresses the dynamic of social -tech approach at individual and organisational level. An integrated framework gives a better understanding of both elements of social as well as technical, bridges the gap of micro level analysis associated with ANT and offers opportunity to employ different research methods to unveil the scope of the study. The evolution of technologies has been studied in different perspectives. It differs according to the context and has consistently been refined by different researcher because they are found to be unstable and often undergo changes such as in the case of internet applications (Orlikowski, 2002). This implies that the evolution of emerging technology, its development and adoption process is not a "onetime decision but a continuous process of living with the evolving innovation" Ng-Kruelle, Rebne, Swatman and Hampe (2005 :) and it always follow a recursive interaction of actors at different stage 


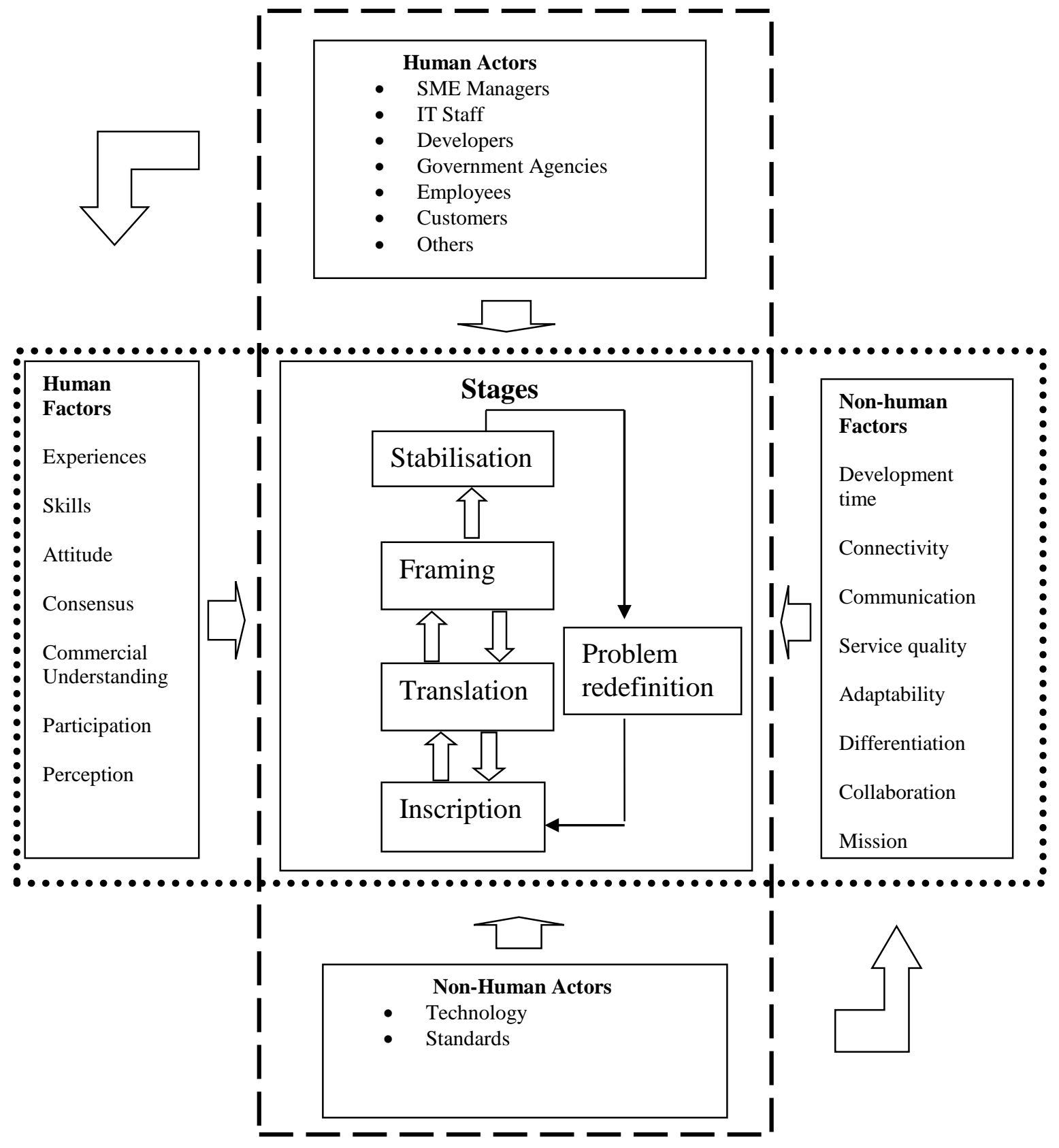

Figure 1: Emerging ICT adoption Framework

\section{CONTRIBUTIONS}

Several models have been developed and used in adoption research. These theories have provided insights on adoption studies; however, one of the key challenges facing most of the theories is that they do not reflect the level of complexities and diversity involved in emerging ICT adoption despite studies (Vessey et al., 2002; Venkatesh et al., 2003; Brown et al., 2010; Eze et al 2011) continually emphasising that one of the most mature streams in information systems (IS) research is technology adoption. One of the reasons for this is the availability of theories developed unveiled in this study which have been applied in different settings and contexts (Brown et al., 2010). Studies have relied so much on these theories and ignored the fact that ICT follows an unpredictable path. Most studies in this area have ignored the fact that 
as the business environment changes, so do organisations constantly witness changes in technological applications especially those of internet with new digital platforms for social, business networking and formation of communities (Vannoy and Palvia, 2010). The failure on the part of researchers to understand this has always led them to investigate ICT adoption from two dominant streams (ether social or the technical aspect).

The framework demonstrates that it is social-technical phenomena that take into account a mutual understanding of diverse actors that share their views and influence the development of new technology. Inevitability, it reveals that the ICT and the social aspect of development and adoption must be intertwined in order to achieve both the economic and social impact. Focusing on the social-technical nature of technology adoption, the research was able to reveal a number of questions regarding the holistic development of emerging ICT and adoption such as; how do new ICT originate in the context of small business?; various actors that are involved in the initiation and interpretation of the technology?; how the new technology is institutionalised and the unexpected change that leads to reformulation of interest?

The integrated framework exemplifies ongoing struggles for the creation, adoption and adaptation of new ICT and identifies potential factors that might influence the process since the way actors interpret their interests embedded in the technology is flexible just as human actors' interests are adaptable, to capture the flexibility, adaptability and predictive nature, require multiple representation of context including the social and technological aspect of both human and non-human (Gao, 2005). Although this factors are not exclusive empirical work in this area will be necessary to determined factors that constantly influence the process. The potential factors have been grouped under the following headings-human and non-human factors. Human factors are those factors directly associated with human actors, while nonhuman factors are defined as those factors linked to non-human actors. It is important to note that the human actors and non-human actors were identified during the preliminary investigation.

\section{CONCLUSION}

The literature review suggests that the emerging paradigm (that is where users and consequences of technology emerge from unpredictable and complex social interaction) is able to unveil the issues (Markus and Robey, 1998). This paradigm provides new opportunities for researchers but most importantly, challenges the underlying ideas and assumptions in which most prominent theories of ICT adoption were developed; however, this perspective is still absent in the literature (Markus and Robey, 1998). An attempt to understand he multiple, emergent and the social-technical entities involved in emerging ICT adoption which today stands as the contemporary organisations norms (Orlikowski and Scott, 2008) remains fundamental for progressive research in this field. Markus and Robey, (1998) note that this perspective considers technology as part of a complex process through which organisations accomplish tasks, and focuses on the dynamic interactions between people and technology over time (Orlikowski and Scott, 2008). Therefore, scholarly attempts should not limit to either the technical or the social instead, it is worthwhile to consider their recursive interactions when making theoretical and empirical advancements in this area. 


\section{REFERENCES}

Akrich M. Callon M. and Latour B. (2002). "The Key to Success in Innovation Part 1:The Art of Interessement." International Journal of Innovation Management 6(2): 187-206.

Akrich M. Callon M. and Latour B. (2002). "The Key to Success in Innovation Part 11: The Art of Choosing Good Spokespersons." International Journal of Innovation Management 6(2): 207-225.

Allen J. (2004). "Redefining the Network: Enrolling Strategies in the PDA industries." Information Technology and People 17(2): 171-185.

Barrett M. Grant D. and Wailes N. (2006). "ICT and Organisitation Change: Introduction to Special Issue." The Journal of Applied Behavioural Science 42(1): 6-22.

Bijker, W. E. \& Law, J. (eds.) 1992. Shaping technology building society:Studies in socialtechnical change, Cambridge ,Massachusetts: The MIT Press.

Bijker W. E. Hughes T. P. and Pinch T., Ed. (1989). The social construction of Technology Systems. New Direction in the Sociology and History of Technology. USA, Maple -Vail, Inc.

Bostrom, R. P., Gupta, S. \& Thomas, D. 2009. A meta-theory for understanding information systems within social technical systems. Journal of Management information Systems, 26(1), 17-47.

Brown, S. A., Dennis, A. R. \& Venkatesh, V. 2010. Predicting collaboration technology use :Integrating technology adoption and collaboration research. Jouural of Management Information Systems, 27(2), 9-53.

Callon M. (1986). Some Elements of Sociology of Translation: Domestication of the Scallops and the Fishermen of Brieuc Bay. In J. Law. Power, Action and Belief: A New Sociology of Knowledge (pp. 196-223) London, Routledge

Desanctics, G. \& Poole, M. S. 1994. Capturing the complexity in advanced technology use: Adaptive Structration Theory. . Organisation and Science 5(2), 121-147.

Eze, S., Duan, Y. \& Jackson S. (2011). Understanding the dynamic process of emerging ICT adoption In UKservice SMEs. Proceeding of the 16th Annual Conference 2011 UK Academy for Information Systems. Oxford UK.

Eze, S., Duan, Y. \& Chen, H. (2012). Factors Affecting Emerging ICT Adoption in SMEs: An Actor Network Theory Analysis. International Conference on E-business Technology \& Strategy (ICETS). Tanjin,

China.

Eze S.,Dean Y\& Chin H.(2014) Examining Emerging ICT's Adoption in SMEs from a dynamic Process Approch. Information Technology and People 27(1),63-82

Eze S., (2013) Understanding Dynamic Process of Emerging ICT Adoption in UK Service SMEs.An Actor Network Approch .PhD thesis, University of Bedfordshire UK

Faraj S. Kwon D. and Watts. (2004). "Contested Artifact: Technological Sense Making, Actor Networks and the Shaping of the Web Browser." Journal of Information, Technology and People 17(2): 186-209.

Gao P. (2005). "Using Actor-Network Theory to Analysis Strategy Formation." Information Systems Journal 15(15): 225-275

Garud, R. \& Rappa, M. A. 1994. A social -conitive model of technology evolution:the case of cochlear implants. Organisation Science, 5(3), 344-362.

Hanseth O. Aanestad and Berg M. (2004). "Guest Editor' Introduction: Actor network Theory and Information Systems. What's so special?." Information, Technology and People 17(2): 116-123. 
Latour B.,(1999). On Recalling ANT' in Law J and Hassard Actor Network Theory and After (pp15-25). Oxford, Balckwell Publishing

Latour B. (2005). Reassembling the Social: An Introduction to Actor-network-Theory. Oxford, Oxford University Press

Lee H. and Oh S. (2006). "A Standards war waged by a developing country: Understanding international standard setting from the actor -network perspective." Strategic Information Systems 15: 177-195

Mahring M, H. J., Keil M and Montealegre R., (2004). "Trojan Actor Networks and Swift Translation: bring Actor-Network Theory to Project Escalation Studies." Information Technology and People 17(2): 210-238.

Markus M.L and Robey D. (1998). "Information Technology and Organisational Change: Causal Structure in Theory and Research." Management Science 34(5): 583-598.

Orlikowski, W. J. \& Scott, S. V. 2008. Sociomateriality:Challenging the separation of technology London,: London School of Economics and Political Science.

Sarker S. Sarker S. and Sidorova A. (2006)."Understanding business process change Failure: An Actor Network Perspective" Journal of Management Information Systems 23(1): 5186.

Tatnll A. and Leoa J. (2003). "The Internet E-commerce and Older People: An Actor-Network Approach to Reasons for Adoption and Use " Logistic Information Management 16(1): 56-63.

Vannoy S A. and Palvia P. (2010). "The Social Influence Model of Technology Adoption." Communications of the ACM 53(6): 149-153.

Venkatesh, V. \& Davis., F. 2000. A theoretical extension of the technology acceptance model: four longitudinal field studies. Management Science, 46(2), 186-204.

Venkatesh, V., Morris, M. G., Davis, G. B. \& Davis, F. D. 2003. User acceptance of information technology:Toward a unified view. MIS Quarterly, 27(3), 425-478.

Vessey, I., Ramesh, V. \& R . L Glass . 2002. Research in information systems: An empiricalstudy of diversity in the discipline and its journals. Journal of Management Information Systems, 19(2), 129-174. 